\title{
Vivienda en altura en zonas de renovación urbana: Desafíos para mantener su vigencia
}

Pablo Contrucci Lira Arquitecto Pontificia Universidad Católica de Chile

Uno de los fenómenos urbanos más evidentes presente en las últimas décadas en Santiago es el proceso de renovación urbana del centro de la ciudad, caracterizado por la irrupción de un mercado inmobiliario nuevo destinado a vivienda económica en altura. El impacto es aún más notorio por el contraste que produjo con la situación precedente de declinación y abandono. Efectivamente, desde fines de los 60 la comuna de Santiago y las áreas pericéntricas de las comunas aledañas sufrieron un progresivo deterioro tanto en calidad del stock construido como en superficie edificada nueva y de rehabilitación. La vivienda prácticamente dejó de construirse llegando a su punto más bajo en 1983, año en que tuvo una participación del 0,04\% del mercado residencial de la ciudad, en términos de unidades edificadas, lo que es casi despreciable. Peor todavía, las superficies que se construían o remodelaban tenían destinos generalmente expulsivos de residentes: bodegas, talleres, moteles e industria. Otra gran superficie se destinaba - sin construcción ni habilitación alguna- a playas de estacionamiento vehiculares y a sitios vacíos de acopios transitorios. De esta manera, la comuna de Santiago llegó a perder más de la mitad de los habitantes que tuvo en su momento de mayor población, 1940 (444.000 hab.). El censo de 1992 indicó 231.000 habitantes y el de 2002 confirmó la pérdi$\mathrm{da}$, aunque con menor fuerza al llegar a 201.000 habitantes.

El proceso de revitalización puesto en macha logró muchos objetivos; sin embargo, la pérdida de población se mantiene y se espera siga bajando asociada a otros fenómenos poderosos, como la disminución de la tasa de ocupación de las viviendas, la que a su vez se correlaciona con mayores ingresos per cápita y cambios de modos de habitar de los residentes céntricos. Es decir, la pérdida de población entre 1940 y 1990 tuvo como signo la pérdida de vigencia y energía. En cambio la pérdida de población reciente tiene asociado un signo de recuperación del territorio central. Está por verse si en el período intercensal 2002-2012 ganará uno u otro signo.

\footnotetext{
Este artículo se basa en la versión diciembre 2010 de la Memoria Explicativa PRMS 100 (ver http://www.seremi13minvu.cl/ opensite_20110103164100.aspx).

Como premisa a este artículo, el autor aclara que, en su opinión, el límite urbano constituye un instrumento de planificación válido y necesario, que por su naturaleza puede y debe ser modificado cuantas veces sea necesario.
} 
A partir de mitad de la década del 90 comenzó la recuperación de la actividad de la construcción y de la oferta de vivienda nueva en el centro de Santiago, como consecuencia del Programa de Repoblamiento impulsado por la Municipalidad de Santiago por intermedio de la Corporación para el Desarrollo de Santiago y de la creación del Subsidio de Renovación Urbana por parte del Ministerio de Vivienda y Urbanismo ${ }^{1}$. Desde fines de los 90 la comuna de Santiago pasó a ser la comuna que más departamentos vende en el país y se posicionó claramente como líder en la renovación urbana residencial. Esta nueva situación ofrece un panorama con importantes efectos positivos y varios negativos que interesa analizar para perfilar los desafíos que vienen por delante.

Entre las consecuencias urbanas positivas es posible verificar cómo la inclusión de vivienda nueva ha generado intensificación urbana detectable en el aumento de la oferta comercial, tanto en cantidad como en calidad y en la diversidad de los rubros comerciales. Esto se traduce en una vida urbana de horario más extendido debido a la actividad gastronómica y de esparcimiento que complementan las de los servicios y oficinas. Esta intensificación urbana no es consecuencia exclusiva del repoblamiento. También se apoya en la nueva vigencia de estos mismos barrios como lugares de estudios superiores. Ambas actividades -residencia y universidadson complementarios positivos en este territorio. Una tercera actividad puesta en valor en el mismo territorio en este período ha sido la actividad gastronómica como resultado de un reposicionamiento de los barrios antiguos pericéntricos de Santiago. Este fenómeno es aún incipiente -no se puede hablar todavía de un verdadero polo gastronómico-, pero ha posibilitado progresivamente la instalación de restoranes de mejor categoría en torno a la Plaza Brasil, sobre la calle Cummings y más difusamente en el Barrio Yungay.

Como consecuencia de lo anterior, es posible configurar un futuro relativamente auspicioso para la integración de actividades urbanas en los barrios renovados. Las dudas van por el lado de los usos que generan mayor fricción con la actividad residencial: por ejemplo, la actividad universitaria trae asociadas actividades menos deseables como los bares y la a veces excesiva vida en la vía pública de los propios estudiantes, que generan molestias a los residentes.

Una de las amenazas más señaladas por quienes a comienzos de los 90 objetaban la redensificación de áreas céntricas era la congestión vehicular y la contaminación ambiental. El tiempo ha demostrado que la congestión vehicular en los barrios más renovados no ha sido tal. Los nuevos residentes, en general, son

1 En 1992 la Corporación para el Desarrollo de Santiago puso en marcha el Programa de Repoblamiento que mediante la facilitación del encuentro entre oferta y demanda logró activar la construcción de edificios residenciales en barrios deteriorados. Por su parte, el Ministerio de la Vivienda, a partir de 1993, generó una línea de subsidio especial (llamado Subsidio de Renovación Urbana) que bonifica la compra de viviendas en zonas declaradas de Renovación Urbana por sobre el subsidio habitacional tradicional de los programas regulares del ministerio (Decreto Supremo 40) con el objeto de incentivar la construcción de viviendas en zonas deterioradas de todo el país. Este subsidio ha tenido un efecto sobresaliente en la comuna de Santiago. Consiste en un bono de 200 U.F. (aproximadamente USD 8.800). 
poco dependientes del automóvil. En el mismo tiempo, las líneas de metro se han extendido agregando accesibilidad a Santiago Poniente y el Transantiago logró ordenar y disminuir el impacto negativo que tenían los miles de buses amarillos del sistema antiguo que cruzaban estos barrios céntricos. La renovación del transporte logró disminuir la cantidad de buses, mejorando su estándar técnico -incluyendo el ruido generado- y diversificando los recorridos.

Desde el punto de vista ambiental, también hay que reconocer que, en el período que analizamos, la calidad del aire -la polución más sensible para este tema- ha dejado de aumentar sostenidamente y ha salido de la queja ciudadana como principal problema para vivir en zonas intensamente urbanas.

El efecto más negativo de la construcción masiva de edificios residenciales en altura está en el plano de la imagen urbana y del skyline. La irrupción de edificios de altura en barrios de construcción baja, a veces reemplazando arquitecturas crecientemente valoradas por la sociedad, es claramente la queja ciudadana más sensible. De hecho, la Municipalidad de Santiago ha debido ir adecuando el Plano Regulador Comunal de manera de restringir progresivamente la altura y otras variables de impacto negativo. Estas modificaciones se han hecho barrio a barrio, en la medida que los efectos más perniciosos se van manifestando. Por lo tanto, muchos de los modelos edificatorios que provocan la queja ciudadana ya no son posibles de replicar. El problema es que al bajar el potencial de desarrollo el Plan Regu- lador está desplazando la energía hacia otros lugares.

Otro problema urbano que es particularmente acucioso y complejo de resolver se refiere al efecto que produce la discontinuidad de la actividad inmobiliaria en el territorio. Me refiero a que si en una manzana un promotor inmobiliario toma posición y construye un gran edificio, sacándole el mayor partido a la normativa en términos de superficie vendible y, por lo tanto, de altura y volumen, el resto de la manzana entonces deja de tener atractivo para construir otro edificio. Esto se debe a que ya perdió parte de las vistas y del asoleamiento o porque por su configuración y normativa resulta poco rentable su desarrollo. La siguiente operación inmobiliaria va a ser probablemente en la manzana del frente, pero no en esta misma. Y la manzana del primer edificio queda sin energía precisamente porque ya perdió parte de su potencial. Esto es particularmente notable en vías que tienen ensanches planificados, ya que se suma la pérdida de potencial que ese gravamen ejerce sobre los lotes disponibles. Baste observar la avenida Santa Isabel.

El problema radica en que los planes reguladores tienden a ser diseñados con demasiada influencia del sector inmobiliario. Es natural que un municipio busque captar la actividad inmobiliaria. Es por ello que la capacidad constructiva que permiten los planes reguladores tiende a cumplir con la ecuación de la rentabilidad, de lo contrario la energía inmobiliaria se escaparía a otros sectores más permisivos. En una ciudad 
como Santiago, con 38 comunas prácticamente independientes y competitivas en este aspecto, esto es potenciado por la falta de normativa de nivel superior a escala metropolitana. Cada comuna elabora su Plano Regulador y quiere captar el potencial inmobiliario. Eso termina en que la mayoría de los planes reguladores en Chile tienen potencial edificatorio sobredimensionado para la real energía inmobiliaria y, como consecuencia, permiten el gran y único edificio de alta rentabilidad.

Para ir en sentido contrario, es decir, repartir la carga de manera de producir mayor continuidad de potencial inmobiliario y, como consecuencia de ésta, una forma construida más continua, se debe necesariamente pasar por una revisión profunda, no de los Planes Reguladores en sí -no se le puede pedir peras al olmo-, sino de la lógica con que se diseñan éstos, del modelo urbano que debieran promover y de la estructura jurídica que lo sustenta. La verdad es que la manera en que hoy se diseña un plano regulador en zonas de alta demanda constructiva pocas veces tiene que ver con un modelo buscado. Más bien trata de resolver la ecuación de rentabilidad de la manera menos perjudicial. Mientras eso no cambie, seguiremos teniendo una ciudad que se renueva "diente por medio". Se requiere de una vez por todas elaborar mecanismos más complejos pero efectivos como la transferencia de derechos de edificación que tantos años lleva en Chile sin una discusión seria.

Cuando el análisis baja al nivel del producto construido, es decir, a los edificios y los departamentos habitacionales, el panorama también exige propuestas innovadoras.

Sin duda ha habido mejoras en el diseño, equipamiento y calidad de los edificios residenciales en estos barrios, así como en todo el país como consecuencia de un mercado más exigente y de mayor valor agregado por parte de inmobiliarias líderes. Es evidente que actualmente la demanda ya no acepta edificios de diseño rústico y en cambio favorece diseños más elaborados. En este sentido es muy impactante comparar la imagen, incluso la publicidad y el marketing de los edificios construidos en la década del 90 con los más recientes. Esta modernización fue difícil de comprender en un comienzo por parte de las inmobiliarias. En general éstas tenían la idea de un mercado más asociado a las lógicas de la vivienda social en donde el cliente acepta diseños básicos a cambio de beneficios más sensibles como el precio y la localización. Todavía falta en este aspecto que las inmobiliarias entiendan que deben mejorar otros estándares. Por ejemplo, es raro que superen la cantidad de plazas de estacionamiento exigidas por la norma. Aún no internalizan el hecho de que la demanda de estacionamientos está por sobre la normativa en estos barrios céntricos. Los residentes usan poco el automóvil, pero la gran mayoría tiene uno al menos y necesita un lugar para guardarlo.

En el mismo ámbito del diseño quedan desafíos por superar tan importantes como mejorar la calidad de los materiales para bajar costos de mantención, dis- 
minuir el deterioro y con eso disminuir la pérdida de valor que éste trae a los departamentos en altura. Efectivamente, la proliferación de estucos rugosos pintados como material de terminación de fachadas -a veces de superficies gigantescas en medianeros ciegos de gran altura- es una condena segura a deterioro de la imagen de los edificios. Comunidades compuestas a veces por varios cientos de pequeños propietarios son difíciles de organizar cuando llegue la hora de invertir en la costosa renovación de estas fachadas. Más aún cuando parte importante de las unidades de departamentos son propiedad de personas rentistas que no viven en el lugar y no ven beneficio directo en asumir la mantención de los edificios.

Otros elementos de impacto negativo en el plano del diseño arquitectónico y en la administración de los conjuntos tienen que ver con particularidades del diseño habitacional en altura en Chile. En la industria existe una especie de obligatoriedad de diseñar con muchas ventanas en el plano de la fachada, en lo posible ventanas de piso a cielo con un diseño mínimo de la fenestración, es decir, las ventanas no son más que un simple rasgo en el muro, "cajas con hoyos" como diría un ciudadano común. Sin embargo, no se regula el material ni el color de las cortinas que ponen los residentes por el interior de esas ventanas. Esto se traduce en fachadas revestidas en ventanas de colores distintos, poco armoniosos, definidos más por las tiendas comerciales de hogar que por una visión coherente y unitaria del conjunto. La multitud de cortinas con diseños estampados o colores diversos termina decidiendo la imagen del edificio.

Si, por el contrario, las comunidades regularan el color y el material de las cortinas y los arquitectos supieran convencer a las inmobiliarias de la necesidad de darle atención al diseño de los rasgos para las ventanas, otro sería el efecto. (Póngale un buen dintel y un buen alféizar: ¡no se viene abajo el negocio!).

Algo parecido sucede con la construcción de balcones. Pareciera que en Chile no se puede vender un departamento si no tiene balcones, aunque se trate de un piso 27 en donde es prácticamente imposible usar ese espacio con un nivel de confort mínimo. Lo que sucede entonces, cuando el propietario se da cuenta de la inutilidad de esos metros cuadrados, es que estos espacios son cerrados con ventanas hechizas, fuera de norma, o bien usados como bodegas acopiando ahí bicicletas, cajas, electrodomésticos, aparatos para ejercicios físicos y máquinas de todo tipo que quedan a la vista de toda la ciudad.

Se requiere revisar la normativa de la copropiedad inmobiliaria en estos aspectos urgentemente. La convivencia en estas comunidades de cientos de propietarios es naturalmente muy compleja y nuestra normativa muy simple y básica. IEURE 